\title{
Health and Economic Burden of Running-Related Injuries in Dutch Trailrunners: A Prospective Cohort Study
}

\author{
Luiz Carlos Hespanhol Junior ${ }^{1}$ - Willem van Mechelen ${ }^{1,2,3,4} \cdot$ Evert Verhagen $^{1,3,5}$
}

Published online: 25 May 2016

(c) The Author(s) 2016. This article is published with open access at Springerlink.com

\begin{abstract}
Background Trailrunning is becoming very popular. However, the risk and burden of running-related injuries (RRI) in trailrunning is not well established.

Objective To investigate the prevalence, injury rate, severity, nature, and economic burden of RRIs in Dutch trailrunners.
\end{abstract}

Electronic supplementary material The online version of this article (doi:10.1007/s40279-016-0551-8) contains supplementary material, which is available to authorized users.

Luiz Carlos Hespanhol Junior

1.hespanhol@outlook.com

1 Amsterdam Collaboration on Health and Safety in Sports, Department of Public and Occupational Health and the EMGO+ Institute for Health and Care Research, VU University Medical Center Amsterdam, Van der Boechorststraat 7, 1081 BT Amsterdam, The Netherlands

2 School of Human Movement and Nutrition Sciences, Faculty of Health and Behavioural Sciences, University of Queensland, Brisbane, QLD, Australia

3 UCT/MRC Research Unit for Exercise Science and Sports Medicine (ESSM), Department of Human Biology, Faculty of Health Sciences, University of Cape Town, Cape Town, South Africa

4 School of Public Health, Physiotherapy and Population Sciences, University College Dublin, Dublin, Ireland

5 Australian Centre for Research into Injury in Sport and its Prevention, Federation University Australia, Ballarat, VIC, Australia
Methods This prospective cohort study included 228 trailrunners aged 18 years or over (range 23-67), and was conducted between October 2013 and December 2014. After completing the baseline questionnaire, the Oslo Sports Trauma Research Center Questionnaire on Health Problems was administered every 2 weeks to collect data on RRIs. Participants who reported RRIs were asked about healthcare utilization (direct costs) and absenteeism from paid work (indirect costs). RRI was defined as disorders of the musculoskeletal system or concussions experienced or sustained during participation in running.

Results The mean prevalence of RRIs measured over time was $22.4 \%$ [95\% confidence interval (CI) 20.9-24.0], and the injury rate was 10.7 RRIs per $1000 \mathrm{~h}$ of running (95\% CI 9.4-12.1). The prevalence was higher for overuse (17.7\%; $95 \%$ CI 15.9-19.5) than for acute $(4.1 \%$; $95 \%$ CI 3.3-5.0) RRIs. Also, the injury rate was higher for overuse $(8.1 ; 95 \%$ CI $6.9-9.3)$ than for acute $(2.7 ; 95 \%$ CI 2.0-3.4) RRIs. The median of the severity score was 35.0 [25-75\%, interquartile range (IQR) 22.0-55.7], and the median of the duration of RRIs was 2.0 weeks (IQR 2.0-6.0) during the study. The total economic burden of RRIs was estimated at $€ 172.22$ (95\% CI 117.10-271.74) per RRI, and $€ 1849.49$ (95\% CI 1180.62-3058.91) per $1000 \mathrm{~h}$ of running. An RRI was estimated to have a direct cost of $€ 60.92$ (95\% CI 45.11-94.90) and an indirect cost of $€ 111.30$ (95\% CI 61.02-192.75).

Conclusions The health and economic burden of RRIs presented in this study are significant for trailrunners and for society. Therefore, efforts should be made in order to prevent RRIs in trailrunners. 


\section{Key Messages}

At any given time, one in five trailrunners report having a running-related injury (RRI).

Of the RRIs in trailrunners, $75.2 \%$ were overuse injuries, and the prevalence of overuse RRIs was fourfold higher than acute RRIs.

The indirect cost of RRIs (related to absenteeism from paid work) was twofold higher than the direct cost (related to healthcare utilization).

\section{Introduction}

Physical activity is a cost-effective and cost-saving intervention to improve overall health and gain healthy lifeyears [1-4]. There is evidence claiming that physical activity participation in outdoor environments has a larger beneficial effect on physical and mental wellbeing than participation in indoor physical activities [5]. Coincidentally, trailrunning, a mode of running consisting of running in the outdoors on unpaved and hilly/mountain terrains, is quickly gaining in popularity worldwide. The trailrunning community is composed of well trained trailrunners who participate in ultra-marathon events $(>42.2 \mathrm{~km})$, but also increasingly by trailrunning enthusiasts who partake in trailrunning events with shorter distances.

Running is a very popular mode of exercise among people seeking an active lifestyle [6,7]. Next to being beneficial for health [8-10], running also carries a risk of running-related injuries (RRI) with incidence rates ranging from 7.7 [95\% confidence interval (CI) 6.9-8.7] to 17.8 (95\% CI 16.7-19.1) RRIs per $1000 \mathrm{~h}$ of running in recreational and novice runners, respectively [11]. However, prospective data on the risk and burden (including costs) of RRIs in trailrunning are sparse, especially in cohorts including trailrunning enthusiasts that compose the general trailrunning population.

Most RRIs have an overuse nature [12] of which the symptoms can last for several weeks [13]. Also, these injuries can negatively influence physical activity participation $[14,15]$. Consequently, measuring overuse injuries next to acute injuries is important to understand the overall burden of RRIs [15]. However, measuring overuse injuries is challenging, because of their non-identifiable and gradual onset, and also due to fluctuation of symptoms over time [16]. Most studies about running have measured RRIs leading to consequences, such as time loss (i.e. running sessions not fully accomplished or completely missed due to RRIs) and/or medical attention [17]. Defining RRI based only on these consequences could underestimate the overall burden of RRIs, since minor injuries not resulting in such consequences would be neglected $[18,19]$. Also, to register overuse injuries accurately, one needs a long follow-up time including regular measurement intervals in order to chart the gradual onset and fluctuations of symptoms related to overuse RRIs $[16,18]$. Such data are sparse in the RRI literature, and completely missing in trailrunning.

The purpose of this study was therefore to prospectively investigate the prevalence, injury rate, severity, nature, and economic burden of acute and overuse RRIs in Dutch trailrunners. Such data may assist in the development of RRI prevention programs in this mode of running, and also may assist in decisions related to allocation of public health financial resources.

\section{Methods}

\subsection{Participants}

This study was composed of a convenience sample of the general Dutch trailrunning population. Individuals engaged in trailrunning were invited to partake in the study via flyer cards distributed during trailrunning events in The Netherlands, and also by social media channels, newsletters, and the MudSweatTrails (MST) website [20]. The flyer cards and additional recruitment sources guided the individuals to the project's website containing further information and the option to enroll in the study. Individuals who agreed to participate through online informed consent, aged 18 years or over, reported running on unpaved surfaces on a regular basis, and who completed the baseline questionnaire were included in the study. A sample size calculation a priori was not possible because of a lack of information on the prevalence of RRIs repeatedly measured over time at the commencement of this study. The study was approved by the medical ethics committee of the VU University Medical Center Amsterdam, The Netherlands.

\subsection{Study Design}

This was a prospective open cohort study conducted between October 2013 and December 2014. This cohort was composed of a dynamic sample, i.e., the participants entered into the study at different time-points and, therefore, they had different follow-up periods. However, all participants were followed for at least 6 months. After giving informed consent, a link to a secure online baseline questionnaire was sent by e-mail to the participants. This 
questionnaire asked about demographics, running experience, participation in other sports, current medical conditions, previous (last 12 months) RRIs, and current RRIs. Online follow-up questionnaires were completed every 2 weeks via a secure link sent by email. The aim of these follow-up questionnaires was to collect data about the participants' running exposure (overall exposure and on unpaved surfaces specifically) and to record any health problems experienced in the preceding 2 weeks. In case of a sustained RRI, information about healthcare utilization and absenteeism from paid work related to the RRI were also registered through the same follow-up questionnaires (conditional branching questions). If no response was received within 1 week, a reminder was sent by e-mail encouraging the participant to complete the follow-up questionnaire.

\subsection{Health Problems Registration}

In order to prospectively register health problems during the follow-up, the translated and adapted Dutch version of the Oslo Sports Trauma Research Center (OSTRC) Questionnaire on Health Problems was included in the followup questionnaires [21, 22]. The OSTRC questionnaire was proposed and validated to register and monitor sports-related health problems over time, i.e., acute injuries, overuse injuries, and illnesses [23]. The internal consistency (Cronbach's $\alpha$ ) of the OSTRC questionnaire was estimated at 0.96 and 0.91 for overall problems (including illnesses) and overuse injuries, respectively [21, 23].

The OSTRC questionnaire consisted of four key questions on: (1) the extent to which injury, illness, or other health problems have affected running participation; (2) running volume; (3) running performance; and (4) the extent to which the individual has experienced symptoms during the previous 2 weeks. If no problems were reported on these four key questions, the questionnaire was finished. If a problem was reported on any of the four key questions, the participant was asked to specify whether the problem was an illness or an injury. In the case of an illness, the questionnaire was finished. In case of an injury, participants were asked to report the anatomical location (one possible answer per RRI), injury type (one possible answer per RRI), a description of the symptoms (open question), injury onset, the number of days of time loss (defined as the number of training sessions not fully accomplished or completely missed due to injury), and whether the injury was related to running. In the case of multiple injuries within the fortnight, the participants were asked to register the injury that caused most complaints. Other injuries could be reported in an open question. Participants were instructed to report all problems, regardless of whether or not they had already reported the same problem in previous follow-up questionnaires.

\subsection{Classification of Health Problems}

Health problems were classified as injuries if they were "disorders of the musculoskeletal system or concussions," and were classified as illnesses if they "involved other body systems" [21]. One investigator who is also a physiotherapist (LCHJ) evaluated each reported injury case by case. Injuries were classified as RRI when they were reported as such by the participants, and when the physiotherapist confirmed that they were experienced or sustained during participation in running. Subsequently, RRIs were subcategorized into acute (the onset could be linked to a specific injury event) or overuse injuries (could not be linked to a clearly identifiable event) [21]. The Orchard Sports Injury Classification System version 10 (OSICS-10) [24] was used to provide a diagnostic classification for each RRI.

Substantial health problems were defined as those leading to moderate or major reductions in training volume, moderate or major reductions in running performance, or complete inability to run, as identified in the response options of the key questions 2 or 3 of the OSTRC questionnaire [21].

A recurrent RRI was defined as an RRI at the same location and of the same type of the index RRI, even if it concerned re-injuries (after full recovery) or exacerbations (not full recovery) [25].

\subsection{Economic Consequences of Running-Related Injuries (RRIs)}

Participants who had reported an RRI were asked about their healthcare utilization (direct costs) and days of productivity loss related to paid work (indirect costs) due to RRIs for the duration of their reporting of symptoms. This information was collected through conditional branching questions in the follow-up questionnaires. The cost evaluation was performed from a societal perspective, considering all RRI-related costs regardless of who pays or benefits [26]. Table 1 provides the cost categories that were registered and related monetary costs used in this evaluation. All prices were standardized to the year 2009 according to the Dutch Health Insurance Board [27] and corrected for inflation until the year 2014 [28]. Costs of absenteeism from paid work were estimated based on the mean income [27] and working hours of the Dutch population according to age and gender [29]. 
Table 1 Monetary costs applied in the cost analysis

\begin{tabular}{|c|c|}
\hline Description & Cost, $€$ \\
\hline \multicolumn{2}{|l|}{ Healthcare costs (direct costs) } \\
\hline General practitioner (per visit, $10 \mathrm{~min}$ ) & 30.79 \\
\hline $\begin{array}{l}\text { General practitioner (per telephone } \\
\text { consultation) }\end{array}$ & 15.40 \\
\hline Medical specialist (per visit) & 79.17 \\
\hline Physiotherapist (per visit) & 39.59 \\
\hline \multicolumn{2}{|l|}{ Costs of productivity loss (indirect costs) } \\
\hline Absenteeism from paid work (per hour)* & $31.22(9.78-43.95)$ \\
\hline \multicolumn{2}{|c|}{$\begin{array}{l}\text { Prices standardized to the year } 2009 \text { according to the Dutch Health } \\
\text { Insurance Board [27] and adjusted for inflation until the year } 2014 \\
\text { [28] }\end{array}$} \\
\hline \multicolumn{2}{|c|}{$\begin{array}{l}\text { * Indirect costs for paid work were estimated based on the mean } \\
\text { income [27] and working hours [29] of the Dutch population } \\
\text { according to age and gender. The value for paid work is the mean } \\
\text { price followed by the minimum and maximal values according to } \\
\text { standardized prices by age and gender, adjusted for inflation [28] }\end{array}$} \\
\hline
\end{tabular}

\subsection{Data Analysis}

Microsoft ${ }^{\circledR}$ Excel $^{\circledR} 2011$ version 14.5.8 (Microsoft Corporation, Redmond, WA, USA) and R version 3.2.3 (R Foundation for Statistical Computing, Vienna, Austria) were used to analyze the data. Descriptive analysis was performed to present baseline and follow-up data. Percentages were calculated for categorical variables. The mean and its $95 \%$ CI were calculated for continuous data with Gaussian distribution, otherwise the median and the 25-75\% interquartile range (IQR) were calculated.

\subsubsection{Prevalence and Injury Rate Calculations}

Prevalence repeatedly measured over time is considered the preferable measure to describe the overall burden of injuries in sports involving overuse injuries [16]. The mean prevalence of RRIs repeatedly measured over time was calculated according to previous recommendations $[16,21,23]$. For each 2-week period, the prevalence was calculated by dividing the number of participants reporting RRIs during that period by the number of total questionnaire respondents during the same period. Thereafter, the mean prevalence and its $95 \%$ CI were calculated by summing all prevalences measured every 2 weeks, divided by the number of 2-week time-periods. The injury rate was calculated by dividing the number of RRIs by the sum of total running exposure in hours [18, 30]. The number of RRIs was calculated based on the number of unique RRIs identified during the follow-up. Results were expressed as the number of RRIs per $1000 \mathrm{~h}$ of running and its $95 \% \mathrm{CI}$.

\subsubsection{Severity}

In order to monitor the progress of the RRIs over time, a severity score ranging from 0 to 100 was calculated for each RRI based on the response options of the four key questions of the OSTRC questionnaire [21]. Average severity scores were calculated by taking the mean of the severity scores measured every 2 weeks for each RRI. The cumulative severity score (sum of the severity scores measured every 2 weeks) was calculated as an estimation of the total impact that each RRI had had over the course of the study. The average and cumulative time loss were also calculated for each RRI as the same manner as the severity score.

\subsubsection{Costs}

Mean direct, indirect, and total costs were estimated per RRI, per $1000 \mathrm{~h}$ of running, and per most commonly reported RRIs. The participants could present more than one RRI during the study, resulting in dependent observations. Therefore, the difference in costs between overuse and acute RRIs were estimated using linear mixed models with random intercept at the participant level, adjusted for the following possible confounders measured at baseline: age, gender, body mass index (BMI), running experience, practice of other sports, chronic condition, medication use, current RRIs, and previous RRIs. As the cost per $1000 \mathrm{~h}$ of running is a rate between cumulative measures at the population level (i.e., sum of costs divided by the sum of total running exposure in hours multiplied by 1000), adjustment for possible confounders was not possible. Cost data are nonparametric, therefore, $95 \%$ CIs were obtained by bootstrapping the data with 2000 replications [31-33], as recommended for economic evaluations [26].

\section{Results}

\subsection{Participants, Response Rate, and Running Exposure}

A total of 228 trailrunners, 171 males $(75.0 \%)$ and 57 females $(25.0 \%)$, were included in the study. The baseline results are summarized in Table 2. Five male participants entered no data in the follow-up questionnaires, corresponding to an attrition rate of $2.2 \%$. As the participants entered in the study in different time-points, they had different follow-up periods. However, all participants were followed for at least 6 months. The median of the followup period was 34.0 weeks (IQR 28.0-36.0), and the response rate measured every 2 weeks was $77.3 \%$ (IQR 57.6-88.1). The median and IQR for the weekly running exposure can be found in Table 3. On average, $22.8 \%$ 
Table 2 Baseline data of the participants

\begin{tabular}{|c|c|c|c|}
\hline & $\begin{array}{l}\text { All participants } \\
n=228\end{array}$ & $\begin{array}{l}\text { Male } \\
n=171\end{array}$ & $\begin{array}{l}\text { Female } \\
n=57\end{array}$ \\
\hline Age, years & $43.4(42.2-44.6)$ & $43.8(42.4-45.2)$ & $42.4(39.9-44.8)$ \\
\hline Height, $\mathrm{cm}$ & $178.9(177.8-180.1)$ & $182.4(181.4-183.4)$ & $168.4(166.8-170.0)$ \\
\hline Weight, kg & $72.5(71.1-74.0)$ & $76.5(75.2-77.9)$ & $60.6(58.9-62.2)$ \\
\hline BMI, $\mathrm{kg} / \mathrm{m}^{2}$ & $22.6(22.3-22.8)$ & $23.0(22.7-23.3)$ & $21.3(20.9-21.8)$ \\
\hline \multicolumn{4}{|c|}{ Total running experience, $n(\%)$} \\
\hline Up to 1 year & $7(3.1 \%)$ & $7(4.1 \%)$ & - \\
\hline $1-2$ years & $18(7.9 \%)$ & $13(7.6 \%)$ & $5(8.8 \%)$ \\
\hline $2-5$ years & $43(18.9 \%)$ & $35(20.5 \%)$ & $8(14.0 \%)$ \\
\hline More than 5 years & $160(70.2 \%)$ & $116(67.8 \%)$ & $44(77.2 \%)$ \\
\hline \multicolumn{4}{|c|}{ Trailrunning experience, $n(\%)$} \\
\hline Up to 6 months & $22(9.6 \%)$ & $16(9.4 \%)$ & $6(10.5 \%)$ \\
\hline $6-12$ months & $38(16.7 \%)$ & $31(18.1 \%)$ & $7(12.3 \%)$ \\
\hline $1-2$ years & $59(25.9 \%)$ & $38(22.2 \%)$ & $21(36.8 \%)$ \\
\hline $2-5$ years & $71(31.1 \%)$ & $56(32.7 \%)$ & $15(26.3 \%)$ \\
\hline More than 5 years & $38(16.7 \%)$ & $30(17.5 \%)$ & $8(14.0 \%)$ \\
\hline \multicolumn{4}{|c|}{ Practice of other sports, $n(\%)$} \\
\hline Yes & $152(66.7 \%)$ & $111(64.9 \%)$ & $41(71.9 \%)$ \\
\hline No & $76(33.3 \%)$ & $60(35.1 \%)$ & $16(28.1 \%)$ \\
\hline \multicolumn{4}{|c|}{ Chronic condition, $n(\%)$} \\
\hline Yes & $40(17.5 \%)$ & $27(15.8 \%)$ & $13(22.8 \%)$ \\
\hline No & $188(82.5 \%)$ & $144(84.2 \%)$ & $44(77.2 \%)$ \\
\hline \multicolumn{4}{|c|}{ Current medication use, $n(\%)$} \\
\hline Yes & $26(11.4 \%)$ & $16(9.4 \%)$ & $10(17.5 \%)$ \\
\hline No & $202(88.6 \%)$ & $155(90.6 \%)$ & $47(82.5 \%)$ \\
\hline \multicolumn{4}{|l|}{ Current RRI, $n(\%)$} \\
\hline Yes & $41(18.0 \%)$ & $33(19.3 \%)$ & $8(14.0 \%)$ \\
\hline No & $187(82.0 \%)$ & $138(80.7 \%)$ & $49(86.0 \%)$ \\
\hline \multicolumn{4}{|c|}{ Previous RRI (last 12 months), $n(\%)$} \\
\hline Yes & $96(42.1 \%)$ & $71(41.5 \%)$ & $25(43.9 \%)$ \\
\hline No & $132(57.9 \%)$ & $100(58.5 \%)$ & $32(56.1 \%)$ \\
\hline
\end{tabular}

Continuous data are given as mean and $95 \%$ confidence interval

$B M I$ body mass index, RRI running-related injury

(95\% CI 20.1-25.6) of the trailrunners participated in trailrunning events every 2 weeks. The median of the distance of the trailrunning events was $28.0 \mathrm{~km}$ (IQR 17.5-39.1), ranging from 3 (minimum) to $230 \mathrm{~km}$ (maximum).

\subsection{Prevalence, Injury Rate, Severity, and Nature of RRIs}

The absolute number, prevalence, injury rate, and severity measures of RRIs can be found in Table 4. A total of 148 participants (66.4\%) reported 242 RRIs during the followup. Of the injured participants, 68 (45.9\%) reported multiple RRIs (i.e., different OSICS-10 diagnostic classifications). The percentage of injured participants who reported other RRIs within the 2-week time-period was $4.7 \%$ (IQR 4.0-7.2).

The mean prevalence of RRIs measured every 2 weeks was $22.4 \%$ (95\% CI 20.9-24.0). For males, the mean prevalence of RRIs was $23.0 \%$ (95\% CI 21.3-24.7), and for females this was $20.7 \%$ (95\% CI 18.2-23.2), with a mean difference of 2.3 percentage points $(95 \% \mathrm{CI}-1.0$ to 5.6). The mean prevalence of RRIs was higher for overuse than for acute RRIs, with a mean difference of 13.6 percentage points (95\% CI 10.3 to 16.9 ).

The injury rate was 10.7 RRIs per $1000 \mathrm{~h}$ of running (95\% CI 9.4-12.1). For males, the injury rate was 11.3 (95\% CI 9.7-12.9), and for females this was 9.1 (95\% CI 6.6-11.6), with an injury rate difference of 2.2 RRIs per $1000 \mathrm{~h}$ of running ( $95 \% \mathrm{CI}-0.7$ to 5.1 ). The injury rate 
Table 3 Running exposure during the follow-up

\begin{tabular}{lccr}
\hline & $\begin{array}{l}\text { All participants } \\
n=223\end{array}$ & $\begin{array}{l}\text { Male } \\
n=166\end{array}$ & $\begin{array}{c}\text { Female } \\
n=57\end{array}$ \\
\hline $\begin{array}{l}\text { Total running exposure } \\
\text { Duration (h/week) }\end{array}$ & $3.5(2.0-5.0)$ & $3.5(2.0-5.0)$ & $3.5(2.0-5.3)$ \\
Frequency (times/week) & $2.5(1.5-3.5)$ & $2.5(1.5-3.5)$ & $2.5(2.0-3.5)$ \\
Distance (km/week) & $33.6(19.5-50.0)$ & $35.0(20.0-50.0)$ & $32.5(17.5-50.0)$ \\
Running exposure on unpaved surfaces & & & $1.5(0.5-2.8)$ \\
Duration (h/week) & $1.5(0.5-3.0)$ & $1.0(0.5-2.0)$ & $1.5(0.5-2.0)$ \\
Frequency (times/week) & $1.0(0.5-2.0)$ & $15.0(6.0-27.5)$ & $16.0(7.5-30.0)$ \\
Distance (km/week) & $15.0(6.0-28.0)$ & & \\
\hline
\end{tabular}

Results are given as median and $25-75 \%$ interquartile range (IQR)

Table 4 Absolute number, mean prevalence measured over time (every 2 weeks), injury rate, and severity measures of running-related injuries (RRIs)

\begin{tabular}{|c|c|c|c|c|c|}
\hline RRIs & Total & Overuse & Acute & Time loss & Medical attention \\
\hline \multicolumn{6}{|l|}{ Overall } \\
\hline Number of RRIs registered & $n=242$ & $n=182$ & $n=60$ & $n=174$ & $n=72$ \\
\hline Prevalence, mean (95 \% CI) & $22.4 \%(20.9-24.0)$ & $17.7 \%(15.9-19.5)$ & $4.1 \%(3.3-5.0)$ & $15.1 \%(14.0-16.2)$ & $5.9 \%(5.1-6.7)$ \\
\hline $\begin{array}{l}\text { Injury rate, number of RRIs per } \\
1000 \mathrm{~h} \text { of running }(95 \% \mathrm{CI})\end{array}$ & $10.7(9.4-12.1)$ & $8.1(6.9-9.3)$ & $2.7(2.0-3.4)$ & $7.7(6.6-8.9)$ & $3.2(2.4-3.9)$ \\
\hline \multicolumn{6}{|l|}{ Severity measures, median (IQR) } \\
\hline Average severity score & $35.0(22.0-55.7)$ & $31.1(20.0-55.0)$ & $37.0(28.0-57.2)$ & $43.0(28.6-63.0)$ & $55.0(34.5-70.2)$ \\
\hline Cumulative severity score & $55.5(28.0-122.0)$ & $63.0(25.2-122.0)$ & $50.0(33.8-116.0)$ & $78.0(37.0-165.0)$ & $132.0(66.0-278.0)$ \\
\hline Average time loss, days & $2.0(0.0-4.7)$ & $2.0(0.0-4.5)$ & $2.8(1.0-5.1)$ & $3.3(1.8-6.0)$ & $4.0(1.5-7.3)$ \\
\hline Cumulative time loss, days & $3.0(0.0-10.0)$ & $3.0(0.0-10.0)$ & $3.5(1.0-8.0)$ & $5.0(3.0-15.5)$ & $12.0(3.0-28.2)$ \\
\hline Duration, weeks & $2.0(2.0-6.0)$ & $4.0(2.0-6.0)$ & $2.0(2.0-4.0)$ & $4.0(2.0-6.0)$ & $6.0(3.5-10.0)$ \\
\hline \multicolumn{6}{|l|}{ Substantial } \\
\hline Number of RRIs registered & $n=131$ & $n=94$ & $n=37$ & $n=120$ & $n=58$ \\
\hline Prevalence, mean (95 \% CI) & $9.9 \%(9.1-10.8)$ & $7.3 \%(6.5-8.0)$ & $2.3 \%(1.4-3.1)$ & $9.4 \%(8.6-10.2)$ & $3.7 \%(3.1-4.3)$ \\
\hline $\begin{array}{l}\text { Injury rate, number of RRIs per } \\
1000 \mathrm{~h} \text { of running }(95 \% \mathrm{CI})\end{array}$ & $5.8(4.8-6.8)$ & $4.2(3.3-5.0)$ & $1.6(1.1-2.2)$ & $5.3(4.4-6.3)$ & $2.6(1.9-3.3)$ \\
\hline \multicolumn{6}{|l|}{ Severity measures, median (IQR) } \\
\hline Average severity score & $54.5(39.9-68.3)$ & $54.5(39.7-68.8)$ & $51.0(41.2-67.3)$ & $54.8(41.1-69.2)$ & $59.6(44.1-76.6)$ \\
\hline Cumulative severity score & $109.0(66.0-198)$ & $113.0(71.2-230.5)$ & $80.0(50.0-159.0)$ & $117.5(66.0-226.0)$ & $168.0(80.0-287.2)$ \\
\hline Average time loss, days & $4.0(2.0-6.8)$ & $4.0(2.0-6.9)$ & $4.0(2.0-6.0)$ & $4.2(2.8-7.0)$ & $5.0(3.0-8.3)$ \\
\hline Cumulative time loss, days & $7.0(4.0-20.0)$ & $8.5(4.0-23.8)$ & $5.0(3.0-16.0)$ & $9.5(4.0-21.5)$ & $14.0(4.0-31.5)$ \\
\hline Duration, weeks & $4.0(2.0-8.0)$ & $5.0(2.0-9.5)$ & $4.0(2.0-6.0)$ & $4.0(2.0-8.0)$ & $6.0(4.0-10.0)$ \\
\hline
\end{tabular}

Substantial RRIs were defined as those leading to moderate or major reductions in training volume, moderate or major reductions in running performance, or complete inability to run

$95 \%$ CI $95 \%$ confidence interval, IQR $25-75 \%$ interquartile range

was higher for overuse than for acute RRIs, with an injury rate difference of 5.4 RRIs per $1000 \mathrm{~h}$ of running ( $95 \% \mathrm{CI}$ 4.1 to 6.8 ).

A total of $54.1 \%(n=131)$ of the RRIs were classified as substantial (i.e., leading to moderate or major reductions in training volume, moderate or major reductions in running performance, or complete inability to run). Fifty-nine RRIs $(24.4 \%)$ neither resulted in time loss nor in medical attention. Overuse RRIs lasted longer and presented a higher cumulative severity score than acute RRIs (Table 4). The most commonly reported RRIs were Achilles tendon injury $(12.8 \%, n=31)$, calf muscle injury $(10.7 \%, n=26)$, knee pain undiagnosed $(8.7 \%$, $n=21)$, and ankle sprain $(7.0 \%, n=17)$. A breakdown list with all RRIs reported during this study can be found in the Electronic Supplementary Material. 


\subsection{Economic Burden of RRIs}

In total, 332 healthcare consultations ( 21 general practitioner, 47 medical specialist, and 264 physiotherapy consultations) and 102 days of productivity loss related to paid work were registered. A total (direct plus indirect) cost of $€ 41,677.13$ was calculated for the 242 RRIs. The direct cost was $€ 14,742.39$ ( $€ 569.64$ related to general practitioner, $€ 3720.99$ related to medical specialist and $€ 10,451.76$ related to physiotherapy consultations) and the indirect cost was $€ 26,934.74$ (related to absenteeism from paid work).

The costs per RRI, per $1000 \mathrm{~h}$ of running and per most commonly reported RRIs can be found in Table 5. Overuse RRIs presented higher physiotherapy costs than acute RRIs, and acute RRIs presented higher costs related to general practitioner than overuse RRIs. There were no statistically significant differences in costs per $1000 \mathrm{~h}$ of running between males and females. Of the four most commonly reported RRIs, calf muscle injuries presented the highest direct and indirect costs.

\section{Discussion}

\subsection{Trailrunners and Running Exposure}

The sample of the current study was composed by Dutch trailrunners who were recruited during trailrunning events, or through trailrunning channels, like the MST website [20], regardless of age, gender, running experience, competition level, or training exposure (e.g., volume and intensity). As presented in Table 3, Dutch trailrunners usually train on paved and unpaved tracks. This could be explained by the fact that most Dutch trailrunners live in city areas, and, therefore, they do not have easy and fast access to trail tracks that usually are composed by rugged, muddy, and/or mountain terrains. However, trailrunners need to train on a regular basis to be prepared for the trailrunning events that usually have longer distances (median of $28 \mathrm{~km}$ in the current study). Therefore, the sample of trailrunners in the current study can be considered representative of the general Dutch trailrunning population. Furthermore, the characteristics of the Dutch trailrunners who participated in this study may also be similar to recreational trailrunners in other countries.

\subsection{Prevalence and Injury Rate of RRIs}

The results of this study have shown that the mean prevalence of RRIs measured every 2 weeks is between 20.9 and $24.0 \%$ (95\% CI) in trailrunners. In other words, one out of five trailrunners may be expected to sustain
RRIs during a 2-week time-period. The prevalence estimates of this study are not comparable with other studies in the literature, since this is the first study to report the prevalence of RRIs repeatedly measured over time in trailrunners. In addition, previous studies on trailrunning have used different methods and RRI definitions [34, 35]. This hampers comparisons. For example, the incidence proportion of lower limb musculoskeletal injuries (22.2\%) found during the Al Andalus Ultimate Trail 2010 held in southern Spain [35] was similar to the prevalence repeatedly measured over time reported in the current study, although these are two different measures.

Hespanhol Junior et al. [15] have used similar methods as the one used in the current study to investigate RRIs in inexperienced runners training for an event. The study design, surveillance system, RRI definition and RRI classifications were the same in both studies, although the population and the follow-up period were different. The mean prevalence of all RRIs and the mean prevalence of overuse RRIs found in the current study were lower than the mean prevalences reported by Hespanhol Junior et al. [15]. This may be explained by differences in running experience [11] and training volume [36] between these two populations.

As explained in the methods, a priori sample size calculation was not possible because of missing information on the prevalence of RRIs repeatedly measured over time in a general trailrunning population at the commencement of this study. However, the study of Hespanhol Junior et al. [15] was recently available. Therefore, a post hoc sample size calculation based on the results reported in Hespanhol Junior et al. [15] and the results of the current study was possible. The sample size was estimated based on calculations for longitudinal studies with repeated measurements [37]. The prevalence of RRIs repeatedly measured over time in the study of Hespanhol Junior et al. [15] was $30.8 \%$ (95\% CI 25.6-36.0), and in the current study was $22.4 \%$ (95\% CI 20.9-24.0). Considering $\alpha=0.05$, $\beta=0.8,17$ repeated measurements (i.e., median of 34 weeks of follow-up with repeated measurements every 2 weeks), a correlation coefficient of the repeated measurements of 0.24 (calculated in the current study for the purpose of this sample size calculation), and a response rate of $77.3 \%$ (reported in the current study), the sample size calculation suggested a cohort of 152 participants. Based on this calculation, the sample size of the current study was appropriate. This calculation may be useful as a reference for sample size calculations for future longitudinal studies with repeated measurements on RRIs.

Comparisons of injury rates of RRIs across studies are difficult because of differences in RRI definitions [11, 17, 19]. However, the time loss injury rate in trailrunners found in the current study [7.7 RRIs per $1000 \mathrm{~h}(95 \% \mathrm{CI}$ 


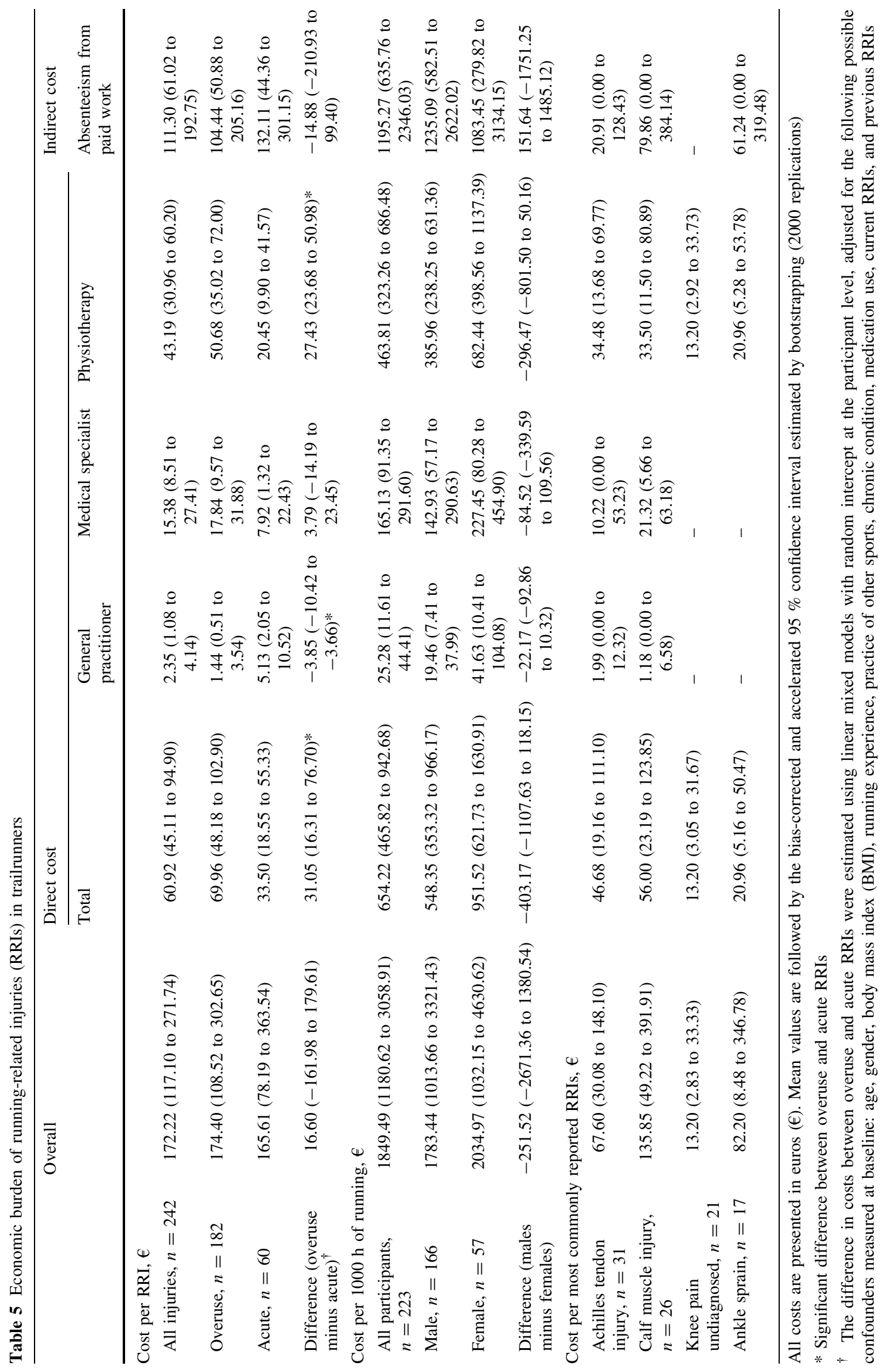


6.6-8.9)] was similar to the injury rate in recreational runners reported by Videbaek et al. [7.7 RRIs per $1000 \mathrm{~h}$ (95\% CI 6.9-8.7)] [11], that was summarized based on studies with time loss RRI definitions.

According to the literature, overuse RRIs occur more frequently than acute RRIs $[12,15]$. The results of the current study support this observation for trailrunning, since the prevalence of overuse RRIs was fourfold higher than acute RRIs, and the injury rate of overuse RRIs was threefold higher than acute RRIs. Most of the time, running can be described as an aerobic physical activity that requires long duration exertion with few changes in movement patterns. Therefore, overuse injuries with a gradual onset mechanism resulting from repetitive microtrauma would be more expected in trailrunning than injuries with a sudden onset.

\subsection{Severity of RRIs}

Severity measures are important to understand the extent to which sports injuries affect health [38]. A strength of this study was the continuous and valid method used to monitor the severity of sports injuries, irrespective of time loss or medical attention [21]. In fact, $24.4 \%$ of the RRIs reported in this study neither resulted in time loss nor medical attention. Therefore, the results of this study support the hypothesis that measuring RRIs based only on time loss or medical attention definitions will lead to an underestimation of the burden of RRIs.

The longer duration of overuse RRIs can explain why the cumulative severity score was higher for overuse than for acute RRIs. More than half of the RRIs were classified as substantial, meaning that they caused a moderate or major reduction in running volume or running performance, or had caused a complete inability to participate in running. This result supports the hypothesis that RRIs may reach such severity levels that they can lead to dropping out of running participation $[14,15]$. The implication is that RRIs may lower the motivation to participate in running, a great ally against the burden of physical inactivity, which is a leading risk factor for the global disease burden [39] and mortality [40]. In fact, running is effective in reducing mortality and disability [8,9]; however, the adherence to running participation is essential to reach such health benefits $[9,10]$.

\subsection{Economic Burden of RRIs}

To the best of our knowledge, this is the first study reporting the total, direct, and indirect costs of RRIs in trailrunners. The cost per RRI in trailrunners found in the current study was $€ 172.22$ (95\% CI 117.10-271.74), which was comparable to the cost per RRI found in runners training for an event (€173.72; $95 \%$ CI 57.17-318.76) [15] and higher than the costs per RRI found in novice runners ( $€ 83.22 ; 95 \%$ CI 50.42-116.02) [41]. These cost estimates are lower than the economic burden generally reported for sports injuries in other athletic populations [42, 43]. However, comparisons with other sports and populations should be made with caution where the study methods and follow-up periods were different.

Healthcare consultations related to RRIs were threefold higher than the number of days of productivity loss related to paid work. However, the indirect cost of RRIs was twofold higher than the direct cost. Interestingly, the indirect-direct cost ratio was higher for acute RRIs (indirect cost fourfold higher than direct cost) than for overuse RRIs (indirect cost 1.5-fold higher than direct cost), indicating that the productivity loss impact may be higher for acute RRIs. Other studies have also shown higher indirect than direct costs related to sports injuries [43-47]. These results indicate that productivity loss is the main contributor to the economic burden of sports injuries, with a significant impact on societal financial resources. As such, policymakers should always take into account the direct and especially the indirect costs of sports injuries to drive their policies.

To put our results into perspective: according to MST, 7500 people participate in trailrunning events organized by them each year. Based on the results of the current study, one trailrunner runs approximately $3.5 \mathrm{~h}$ per week (i.e., $182 \mathrm{~h}$ per year). Therefore, one could expect to have a total cost related to RRIs of more than $€ 2.5$ million yearly, only accounting for trailrunners participating in the MST events. This figure represents around $0.4 \%$ of all annual sports injury costs in The Netherlands [47]. Although not a large proportion, if RRIs in trailrunning are prevented, maybe hundreds of thousands of euros could be saved and redirected to other public health areas. This assumption shows the financial impact that RRIs in trailrunning could have for society.

There is sound evidence showing that physical activity is a cost-effective method to improve overall health, and gain healthy life-years [1-4]. Evidence also suggests that the health benefits of running outweigh the related risks and costs $[4,8-10]$. Therefore, running may be advised for people who seek to improve their health by means of engaging in strenuous physical activity. Nonetheless, RRIs are a preventable side effect of such active engagement and prevention is warranted. Effective prevention of injuries will not only reduce the individual burden in terms of injury and costs, but will also improve joyful and continuing participation in running. 


\subsection{Limitations}

This study was composed of a convenience sample. As presented in Table 4, most RRIs reported in the current study were overuse injuries, i.e., those that have a nonidentifiable and gradual onset, and also present fluctuation of symptoms over time. Consequently, the RRIs reported in the current study represent all RRIs that could be a result of running exposure on paved, unpaved, or both surfaces (the most likely assumption). The RRIs were self-reported and then classified by a healthcare professional (LCHJ) based on the RRI description given by the participants. A confirmation of the RRI diagnoses during face-to-face consultations was not possible due to logistic reasons. Data about medicines taken and diagnostic tests due to RRIs were not collected. This could have lead to an underestimation of the direct costs of RRIs. The cost analysis was an estimation based on Dutch standardized prices for healthcare utilization [27], and the mean income [27] and working hours of the Dutch population for absenteeism from paid work [29], all adjusted for inflation [28]. Despite the fact that this methodology has been accepted and recommended [26], it is important to realize that the cost results were estimated and do not represent actual costs.

\section{Conclusions}

On average, one out of five trailrunners reported RRIs every 2 weeks. Overuse RRIs represented $75.2 \%$ of all RRIs registered during the follow-up. A total of $54.1 \%$ of all RRIs were classified as substantial. The economic burden (direct plus indirect costs) of RRIs was estimated at $€ 172.22$ (95\% CI 117.10-271.74) per RRI, and €1849.49 (95\% CI 1180.62-3058.91) per $1000 \mathrm{~h}$ of running. Healthcare utilization (direct costs) contributed to $35.4 \%$ of these costs and absenteeism from paid work (indirect costs) to $64.6 \%$.

\begin{abstract}
Acknowledgments Luiz Carlos Hespanhol Junior is a $\mathrm{PhD}$ candidate supported by CAPES (Coordenação de Aperfeiçoamento de Pessoal de Nível Superior), process number 0763/12-8, Ministry of Education of Brazil. The authors wish to thank MudSweatTrails and Marc Weening for their assistance during the recruitment, and all trailrunners who participated in this study.
\end{abstract}

\section{Compliance with Ethical Standards}

Funding This study had no funding sources.

Conflict of interest Luiz Carlos Hespanhol Junior and Evert Verhagen declare that they have no conflicts of interest. Willem van Mechelen declares that he is director-shareholder of VU University Medical Center spin-off company Evalua Nederland B.V. (http:// www.evalua.nl), and non-executive board member of Arbo Unie B.V. (http://www.arbounie.nl). Both companies operate on the Dutch Occupational Health Care market.
Ethical approval All procedures performed in studies involving human participants were in accordance with the ethical standards of the institutional and/or national research committee and with the 1964 Helsinki Declaration and its later amendments or comparable ethical standards.

Informed consent Informed consent was obtained from all individual participants included in the study.

Open Access This article is distributed under the terms of the Creative Commons Attribution 4.0 International License (http:// creativecommons.org/licenses/by/4.0/), which permits unrestricted use, distribution, and reproduction in any medium, provided you give appropriate credit to the original author(s) and the source, provide a link to the Creative Commons license, and indicate if changes were made.

\section{References}

1. Codogno JS, Turi BC, Kemper HC, et al. Physical inactivity of adults and 1-year health care expenditures in Brazil. Int $\mathbf{J}$ Public Health. 2015;60(3):309-16. doi:10.1007/s00038-0150657-z.

2. Frew EJ, Bhatti M, Win K, et al. Cost-effectiveness of a community-based physical activity programme for adults (Be Active) in the UK: an economic analysis within a natural experiment. Br J Sports Med. 2014;48(3):207-12. doi:10.1136/bjsports-2012091202.

3. Hagberg LA, Lindholm L. Cost-effectiveness of healthcare-based interventions aimed at improving physical activity. Scand $\mathrm{J}$ Public Health. 2006;34(6):641-53. doi:10.1080/14034940600 627853.

4. Hatziandreu EI, Koplan JP, Weinstein MC, et al. A cost-effectiveness analysis of exercise as a health promotion activity. Am J Public Health. 1988;78(11):1417-21.

5. Thompson Coon J, Boddy K, Stein K, et al. Does participating in physical activity in outdoor natural environments have a greater effect on physical and mental wellbeing than physical activity indoors? A systematic review. Environ Sci Technol. 2011;45(5):1761-72. doi:10.1021/es102947t.

6. Stamatakis E, Chaudhury M. Temporal trends in adults' sports participation patterns in England between 1997 and 2006: the Health Survey for England. Br J Sports Med. 2008;42(11):901-8. doi:10.1136/bjsm.2008.048082.

7. Ottesen L, Jeppesen RS, Krustrup BR. The development of social capital through football and running: studying an intervention program for inactive women. Scand $\mathrm{J}$ Med Sci Sports. 2010;20(Suppl 1):118-31. doi:10.1111/j.1600-0838.2010.01123.x.

8. Chakravarty EF, Hubert HB, Lingala VB, et al. Reduced disability and mortality among aging runners: a 21-year longitudinal study. Arch Intern Med. 2008;168(15):1638-46. doi:10.1001/ archinte.168.15.1638.

9. Lee DC, Pate RR, Lavie CJ, et al. Leisure-time running reduces all-cause and cardiovascular mortality risk. J Am Coll Cardiol. 2014;64(5):472-81. doi:10.1016/j.jacc.2014.04.058.

10. Hespanhol Junior LC, Pillay JD, van Mechelen W, et al. Metaanalyses of the effects of habitual running on indices of health in physically inactive adults. Sports Med. 2015;45(10):1455-68. doi:10.1007/s40279-015-0359-y.

11. Videbaek S, Bueno AM, Nielsen RO, et al. Incidence of runningrelated injuries per $1000 \mathrm{~h}$ of running in different types of runners: a systematic review and meta-analysis. Sports Med. 2015;45(7):1017-26. doi:10.1007/s40279-015-0333-8.

12. Lopes AD, Hespanhol Junior LC, Yeung SS, et al. What are the main running-related musculoskeletal injuries?: a systematic 
review. Sports Med. 2012;42(10):891-905. doi:10.2165/116311 70-000000000-00000.

13. Nielsen RO, Ronnow L, Rasmussen S, et al. A prospective study on time to recovery in 254 injured novice runners. PLoS One. 2014;9(6):e99877. doi:10.1371/journal.pone.0099877.

14. Kluitenberg B, van Middelkoop M, Diercks RL, et al. The NLstart2run study: health effects of a running promotion program in novice runners, design of a prospective cohort study. BMC Public Health. 2013;13:685. doi:10.1186/1471-2458-13-685.

15. Hespanhol Junior LC, van Mechelen W, Postuma E et al. Health and economic burden of running-related injuries in runners training for an event: a prospective cohort study. Scand J Med Sci Sports. 2015. doi:10.1111/sms.12541.

16. Bahr R. No injuries, but plenty of pain? On the methodology for recording overuse symptoms in sports. $\mathrm{Br} \mathrm{J}$ Sports Med. 2009;43(13):966-72. doi:10.1136/bjsm.2009.066936.

17. Yamato TP, Saragiotto BT, Hespanhol Junior LC, et al. Descriptors used to define running-related musculoskeletal injury: a systematic review. J Orthop Sports Phys Ther. 2015;45(5):366-74. doi:10.2519/jospt.2015.5750.

18. Hespanhol Junior LC, Barboza SD, van Mechelen W, et al. Measuring sports injuries on the pitch: a guide to use in practice. Braz J Phys Ther. 2015;19(5):369-80. doi:10.1590/bjpt-rbf.2014. 0110.

19. Kluitenberg B, van Middelkoop M, Verhagen E, et al. The impact of injury definition on injury surveillance in novice runners. J Sci Med Sport. 2015;. doi:10.1016/j.jsams.2015.07.003.

20. MudSweatTrails. Home page. Available at: http://www. mudsweattrails.nl. Accessed in 07 March 2016.

21. Clarsen B, Ronsen O, Myklebust G, et al. The Oslo Sports Trauma Research Center questionnaire on health problems: a new approach to prospective monitoring of illness and injury in elite athletes. Br J Sports Med. 2014;48(9):754-60. doi:10.1136/ bjsports-2012-092087.

22. Pluim BM, Loeffen FG, Clarsen B, et al. A one-season prospective study of injuries and illness in elite junior tennis. Scand J Med Sci Sports. 2015;. doi:10.1111/sms.12471.

23. Clarsen B, Myklebust G, Bahr R. Development and validation of a new method for the registration of overuse injuries in sports injury epidemiology: the Oslo Sports Trauma Research Centre (OSTRC) overuse injury questionnaire. $\mathrm{Br} \mathrm{J}$ Sports Med. 2013;47(8):495-502. doi:10.1136/bjsports-2012-091524.

24. Rae K, Orchard J. The Orchard Sports Injury Classification System (OSICS) version 10. Clin J Sport Med. 2007;17(3):201-4. doi:10.1097/JSM.0b013e318059b536.

25. Fuller CW, Bahr R, Dick RW, et al. A framework for recording recurrences, reinjuries, and exacerbations in injury surveillance. Clin J Sport Med. 2007;17(3):197-200. doi:10.1097/JSM. 0b013e3180471b89.

26. van Dongen JM, van Wier MF, Tompa E, et al. Trial-based economic evaluations in occupational health: principles, methods, and recommendations. J Occup Environ Med. 2014;56(6): 563-72. doi:10.1097/JOM.0000000000000165.

27. van Roijen LH, Tan SS, Bouwmans C. Handleiding voor kostenonderzoek, methoden en standaard kostprijzen voor economische evaluaties in de gezondheidszorg. College voor Zorgverzekeringen; 2010.

28. Centraal Bureau voor de Statistiek. CBS StatLine: Consumentenprijzen; prijsindex 1900=100. Available at: http:// opendata.cbs.nl/Dataportaal/index.html?_la=nl\&_catalog=CBS\&_ si=\&_gu=\&_ed=Topics\&_td=Perioden\&tableId=71905ned\& $\$$ filter $=($ substringof(' $\mathrm{JJ}$ '\% $2 \mathrm{CPerioden})) \&$ select=Perioden\%2CInflatie 2\&graphType=bar. Accessed 11 Dec 2015.

29. Centraal Bureau voor de Statistiek. Arbeidsdeelname; kerncijfers (12-uursgrens). Available at: http://statline.cbs.nl/Statweb/
publication/?DM=SLNL\&PA=71738ned $\& D 1=8-10 \& D 2=a \& D 3=$ $\mathrm{a} \& \mathrm{D} 4=0 \& \mathrm{D} 5=1 \& \mathrm{VW}=\mathrm{T}$. Accessed 11 Dec 2015.

30. Knowles SB, Marshall SW, Guskiewicz KM. Issues in estimating risks and rates in sports injury research. J Athl Train. 2006;41(2):207-15.

31. Chaudhary MA, Stearns SC. Estimating confidence intervals for cost-effectiveness ratios: an example from a randomized trial. Stat Med. 1996;15(13):1447-58. doi:10.1002/(SICI)10970258(19960715)15:13<1447::AID-SIM267>3.0.CO;2-V

32. Efron B. Better bootstrap confidence intervals. J Am Stat Assoc. 1987;82(397):171-85. doi:10.1080/01621459.1987.10478410.

33. Efron B, Tibshirani R. Bootstrap methods for standard errors, confidence intervals, and other measures of statistical accuracy. Stat Sci. 1986;1(1):54-75. doi:10.2307/2245500.

34. Hoffman MD, Fogard K. Factors related to successful completion of a 161-km ultramarathon. Int J Sports Physiol Perform. 2011;6(1):25-37.

35. Scheer BV, Murray A. Al Andalus ultra trail: an observation of medical interventions during a 219-km, 5-day ultramarathon stage race. Clin J Sport Med. 2011;21(5):444-6.

36. Gabbett TJ. The training-injury prevention paradox: should athletes be training smarter and harder? $\mathrm{Br} \mathrm{J}$ Sports Med. 2016;50(5):273-80. doi:10.1136/bjsports-2015-095788.

37. Twisk JWR. Sample size calculations. In: Twisk JWR, editor. Applied longitudinal data analysis for epidemiology. 2 ed. Cambridge: Cambridge University Press; 2013. p. 237-42.

38. van Mechelen W. The severity of sports injuries. Sports Med. 1997;24(3):176-80. doi:10.2165/00007256-199724030-00006.

39. Lim SS, Vos T, Flaxman AD, et al. A comparative risk assessment of burden of disease and injury attributable to 67 risk factors and risk factor clusters in 21 regions, 1990-2010: a systematic analysis for the Global Burden of Disease Study 2010. Lancet. 2012;380(9859):2224-60. doi:10.1016/S0140-6736(12)61766-8.

40. WHO. Global health risks: mortality and burden of disease attributable to selected major risks. Geneva: World Health Organization; 2009.

41. Hespanhol Junior LC, Huisstede BM, Smits DW, et al. The NLstart2run study: economic burden of running-related injuries in novice runners participating in a novice running program. J Sci Med Sport. 2015;. doi:10.1016/j.jsams.2015.12.004.

42. King DA, Hume PA, Milburn P, et al. Rugby league injuries in New Zealand: a review of 8 years of accident compensation corporation injury entitlement claims and costs. Br J Sports Med. 2009;43(8):595-602. doi:10.1136/bjsm.2009.061481.

43. Verhagen EA, van Tulder M, van der Beek AJ, et al. An economic evaluation of a proprioceptive balance board training programme for the prevention of ankle sprains in volleyball. Br J Sports Med. 2005;39(2):111-5. doi:10.1136/bjsm.2003.011031.

44. Cumps E, Verhagen E, Annemans L, et al. Injury rate and socioeconomic costs resulting from sports injuries in Flanders: data derived from sports insurance statistics 2003. Br J Sports Med. 2008;42(9):767-72. doi:10.1136/bjsm.2007.037937.

45. Hupperets MD, Verhagen EA, Heymans MW, et al. Potential savings of a program to prevent ankle sprain recurrence: economic evaluation of a randomized controlled trial. Am J Sports Med. 2010;38(11):2194-200. doi:10.1177/0363546510373470.

46. Janssen KW, Hendriks MR, van Mechelen W, et al. The costeffectiveness of measures to prevent recurrent ankle sprains: results of a 3-arm randomized controlled trial. Am J Sports Med. 2014;42(7):1534-41. doi:10.1177/0363546514529642.

47. Schmikli SL, Backx FJ, Kemler HJ, et al. National survey on sports injuries in the Netherlands: target populations for sports injury prevention programs. Clin J Sport Med. 2009;19(2):101-6. doi:10.1097/JSM.0b013e31819b9ca3. 